Boise State University

ScholarWorks

$12-1-2016$

\title{
Understanding How Algorithms Work Persuasively Through the Procedural Enthymeme
}

Kevin Brock

University of South Carolina

Dawn Shepherd

Boise State University

\section{Publication Information}

Brock, Kevin and Shepherd, Dawn. (2016). "Understanding How Algorithms Work Persuasively Through the Procedural Enthymeme". Computers and Composition, 42, 17-27. http://dx.doi.org/10.1016/j.compcom.2016.08.007

\section{(C) $\mathbb{( \Theta \Theta}$}




\title{
Understanding How Algorithms Work Persuasively Through the Procedural Enthymeme
}

\begin{abstract}
Procedure, when discussed in regards to rhetoric, and to "digital rhetoric" in particular, is framed overwhelmingly in regards to game play (and to video games most frequently). We argue that this view needs to be expanded if scholars of rhetoric are to realize how complex humancomputer rhetor systems function in diverse contexts. Such systems do so through procedural enthymemes, which persuade audience agents to action through the apparent logic of a given system. Procedural persuasion occurs most often via strategies that facilitate the agent to assume an active role in "self-persuasion” in order to complete a given enthymeme. In this text, we explore the procedural enthymeme as a rhetorical tactic for human and nonhuman persuasion by looking at three case studies of commonly used technological "matching” systems—search engines (Google), online matchmaking (Match.com), and social networking (Facebook) — that employ procedural enthymemes in order to persuade users toward particular engagements with those systems.
\end{abstract}

\section{Keywords}

digital rhetoric; procedural rhetoric; enthymeme; matching; search; algorithm 
"What you must learn is that these rules are no different than the rules of a computer system. Some of them can be bent. Others can be broken.”

— Morpheus (Laurence Fishburne), The Matrix

\section{Introduction}

For the last two decades, scholars of rhetoric and composition have, with increasing nuance and focus, examined the digital technologies that have become prominent, if not ubiquitous, components of our writing and composing practices. Since scholars of digital rhetoric generally claim to be interested in how rhetors persuade various audiences through both novel and conventional means, this growing interest holds significant promise for our ability to understand and make use of available technologies in more consciously rhetorical ways.

One particularly exciting avenue of exploration has been the recent turn toward procedure and object orientation as a way to recognize overlooked and emerging means of persuasion, especially in regards to rhetorical ecologies wherein nonhuman agents-e.g., organisms, places, ambience — contribute significantly to the dissemination and impact of a particular argument, as explored in diverse ways by such scholars as Marilyn M. Cooper (2011) and Thomas Rickert (2013). However, this engagement with nonhuman rhetorical activity has been relatively limited in regards to technological agents, notwithstanding Scot Barnett's (2010) argument toward an “object-oriented rhetoric” picked up by James J. Brown, Jr. (2011) and others; in particular, procedure — specifically, computational procedure, a fundamental component of digital technology_and its related rhetorical potential remain employed primarily, if not exclusively, as a means of understanding video games specifically rather than diverse procedural systems broadly. It is likely that this narrow view of procedural rhetoric is an unintended consequence of video games serving as the frame and focal point for Ian Bogost’s (2007b) work defining and 
arguing for procedural rhetoric as a concept. Such an emphasis is demonstrated in the relevant praxis-oriented scholarship published by compositionists who look to video games as a way to explore students' inventional practices, such as those related to multimodal composition.

This lack of broader application stemming from the comprehension of procedure as a rhetorical approach and a general descriptive frame for persuasion, needs to be overcome if rhetoricians are to develop a deeper understanding as to how increasingly complex and ubiquitous human-computer rhetor systems/ecologies function. As we will argue, such systems do so through procedural enthymemes. As the enthymeme serves as one of two fundamental approaches to persuasion (alongside the paradigm or example—-see Aristotle I.ii.8), the procedural enthymeme functions to persuade a human or nonhuman agent to action, whether explicitly or implicitly, through the apparent logic of a given system, regardless of whether that logic reflects actuality or other logics existing outside the bounds of that system. Such persuasion occurs often through the employment of strategies that facilitate agents to assume they have performed all relevant persuasive activity on themselves (rather than with the aid, or due to the influence, of another). In this text, we explore the procedural enthymeme as a rhetorical tactic for human and nonhuman persuasion by looking at three case studies of commonly used technological systems that match data results to user queries_-search engines (Google), online matchmaking (Match.com), and social networking (Facebook)—by employing diverse procedural enthymemes that persuade users to engage those systems in particular ways and for particular ends.

\section{What is Procedural Rhetoric?}

Procedural rhetoric, sometimes referred to as computational rhetoric, is, most succinctly, the use of logical systems by one or more rhetors to invent and deliver an argument. Bogost 
(2007b) provided an extensive contextualization for this definition, explaining that procedural rhetoric involves "the practice of persuading through processes in general and computational processes in particular [... It] is a technique for making arguments with computational systems and for unpacking computational arguments others have created” (p. 3). In other words, procedural rhetoric serves as a means by which rhetors might more clearly and fully understand the ways that logical structures and systems work to induce particular audiences to action. Accordingly, one who understands how and why such structures operate can compose arguments more effectively through procedure, although even one who is unaware of how procedures function could still compose a procedural argument. Bogost (2007a) clarified his definition of procedural rhetoric in a short essay in which he stated that "[p]rocedurality is a practice of model-building, and procedural rhetoric is a practice of model-based argument-building” (p. 307). Often, procedural models and structures are obscured or de-emphasized in real-world practice so that rhetors might, to use Richard Lanham's (1993) words, expect or be expected to look "through" rather than "at" them as texts worthy of critical scrutiny (p. 5). In some cases, such obscurity is proportionally related to a structure's ability to successfully persuade certain audiences.

In the field of rhetoric and composition, Bogost's ideas on procedural rhetoric have been taken up most fully by scholars interested in the possibilities for ludic composition, and those ideas are realized most effectively and commonly thus far through the sorts of persuasive video games that Bogost focused on (Storment, 2011; Thominet, 2012). While Bogost did not paint video games as unique, nor did he suggest that play is necessary in order to understand procedure, he has argued that "only procedural systems like computer software actually represent process with process” (2007b, p. 14). On the one hand, games—and the sorts of video games that 
college students are most likely to access or are interested in accessing on a day-to-day basisserve as a perfectly apt medium through which to help them understand and make use of procedural rhetoric, as Matt King (2010) observed in his examination of Bogost, Burke, and the difficulty of creating a procedural system (e.g., video game) that can be kairotic without a constantly changing set of rules or protocols. On the other hand, by filtering so much instruction about procedure through the lens of games, there is a risk that students might comprehend the concept of procedural rhetoric occurring only through games rather than as underlying and realized in other sorts of procedural systems. For example, Richard Colby (2014) has defined procedurality specifically as "the unit operations, systems, and rules that make a game a game" [emphasis added], even while acknowledging the definitions of procedural rhetoric and procedurality that encompass systems outside the bounds of games and game studies (p. 44). Other scholars, like Brian Ballentine (2015), have argued that students should learn "good writing leads to good software” and good software development practices in a broader sense, with video games and the development thereof serving as one available means by which that principle can be demonstrated and explored in depth (p. 32).

A growing number of scholars are making gestures similar to Ballentine's, extending Bogost's work on procedural rhetoric explicitly beyond video games to incorporate other computational texts within its scope and to focus on how those other kinds of texts operate persuasively, such as electronic literature (Brown, 2015), code functions in software cybertexts (Brock, 2012), and code as a kind of legally protected speech (Vee, 2012). Alex Reid (2010) has even questioned whether a "post-procedural rhetoric" might be appropriate in order to connect with the movement in composition studies to "post-process composition," turning from Bogost's focus on games to "a different direction where rhetoric processes are less deterministic and 
become articulated as components in a more complicated assemblage or network” (n.p.). Reid's suggestion toward post-process suggests one of many potential means by which procedure might be understood as a meaningful and significant component of the larger complex ecology that is rhetoric.

Conceptually related to composition's general push toward procedural rhetoric via games and similar software expressions is the recent uptick in public interest in "code literacy" as a means of inspiring more young people to pursue educations and careers in technology and engineering fields (Raja, 2014; Hour of Code, 2015) or to overcome perceived limitations on American competitiveness in the global market (Rushkoff, 2012). This movement is, generally speaking, far more interested in the pragmatic nature of software as functional tool than in the rhetorical potential of that software in influencing various populations to engage it in particular ways or for particular ends. In this educational movement, games are experienced through the construction of their procedural rules in order to provide a sense of empowerment to those tweaking existing games or building entirely new games from the logic uncovered through backend exploration —as the code that runs the game is often made at least partially visible to the student so that he or she can learn relevant procedural structures and relevant code syntax to compose the game's rules for the computer to interpret. However, this knowledge is very commonly gained as a purely technical or functional skill, without a critical awareness necessary for one to understand or question why a procedural system functions as it does. Bogost (2008) implicitly acknowledged this need when he described video games as persuasive procedural systems: "In a video game, the possibility space [of invention through constraint] refers to the myriad configurations the player might construct to see the ways the processes inscribed in the system work” (p. 121, emphasis added). Bogost (2008) built upon this argument, adding that “[a] 
theory of procedural rhetoric is needed to make commensurate judgments about the software systems we encounter everyday [sic] and to allow a more sophisticated procedural authorship with both persuasion and expression as its goal” (p. 125). As Stuart A. Selber (2004) has noted in his work on multiliteracies, students (and citizens more broadly) need to understand not only how computer technologies—or, as we suggest, any procedural system—operate on a functional level but why they do so (e.g., comprehending what social, political, and cultural forces have influenced their development and the reasons for their doing so) and what those technologies or systems do rhetorically to persuade various audiences to act for particular ends.

The existing disconnect between the academic efforts to understand procedural rhetoric and the industrial efforts to train vocationally a generation of programmers works against both prongs of an otherwise resonant movement toward computational literacy. A significant consequence of this failure to connect rhetorical, critical, and functional literacies is the development and perpetuation of a citizen population that is generally unaware of and unable to understand the impacts that the myriad procedural systems in existence-especially networked computational systems—-have on the day-to-day lives of its members (e.g., how shopping habits are influenced or how traffic flows are facilitated) as well as on the larger-scale trajectories of individual cultures and societies (e.g., the ability of a political campaign to mobilize key demographics or the access one country's agencies have to the telecommunications activities of suspected enemies on the other side of the planet). In other words, there can be no significant social or political change in how these systems influence activity if it is difficult or impossible to recognize those influences.

There are two complementary exigences to which scholars of rhetoric should respond. On the one hand, there is a need to engage and educate populations on the significance of already 
existing procedural systems and their rhetorical agency. On the other hand, there is an obligation among scholars interested in rhetoric, software, and 21st century culture to acknowledge, recognize, and scrutinize these systems and how they are used so as to educate citizens in a more informed and critically aware manner. If rhetoricians are to take up this second need directly, there must first be an understanding as to how a procedural system works. Specifically, we must consider how a procedural system can operate rhetorically and how this rhetorical action hinges on the successful construction and execution of a procedural enthymeme.

\section{The Enthymeme and the Procedural Enthymeme}

According to Aristotle, the enthymeme is, along with the example, one of two primary tools for logical persuasion available to a rhetor (1991, I.ii.8). The enthymeme functions by inviting an audience into the persuasive act and asking that audience to create a seemingly logical connection between two or more ideas—optimally, ideas the audience is already inclined to accept as related in some way (whether from a pre-existing belief or from some preparatory work performed by the rhetor as part of a specific argument). This relation is not always clearly or reliably articulated, and, as Maxine C. Hairston (1986) has observed, Aristotle recommends the enthymeme as an appropriate tool “when the speaker’s concern is human affairs and when the speaker's goal is to establish probability, not certainty. Such discourse does not require the formal structures of scientific inquiry” (p. 62). Indeed, the enthymeme is perhaps most potent when available argumentative structures provide enough room for audience engagement that said audience works to understand the conclusions to which a speaker leads it.

In many cases, the enthymeme is described as an incomplete syllogism, although a number of scholars have argued that this is not always an accurate explanation. When demonstrated by the classic example of the "incomplete syllogism" echoed in the vast majority 
of texts that define Aristotle's enthymeme and how it works, the enthymeme can be understood thusly:

Socrates is human. (premise)

Therefore, Socrates is mortal. (conclusion)

The logic seems sound only if one is willing to recognize (and accept) the missing premise that Socrates’ mortality is connected to his humanity because all humans are mortal. The invention of this initially absent piece of the syllogistic puzzle is a requirement for the claim to have any strength; if an audience is unwilling or unable to make this logical leap, the argument immediately loses its potency. The enthymeme becomes exponentially more interesting when examined via an example that is less logically sound—after all, it is unlikely any audience would question Socrates' human nature or the mortality of humans in general. An example that may be familiar to rhetoricians is Kenneth Burke’s (1969) enthymemic definition of rhetoric "Wherever there is persuasion, there is rhetoric. And wherever there is 'meaning,' there is 'persuasion'” (p. 172). Slightly reorganized, this transitive enthymeme can be understood as follows:

Where meaning exists, persuasion exists. (premise)

Where persuasion exists, rhetoric exists. (premise)

The implicit conclusion to be reached is that rhetoric exists wherever there is meaning-a position that radically expands the scope of rhetorical communication beyond conventional discourse (i.e., written and spoken argument); Burke defines rhetoric as "the use of language as a symbolic means of inducing cooperation in beings that by nature respond to symbols” (1969, p. 43). This definition has conventionally been understood to refer to humans in contrast to other animals and agents; as Burke (1978) argued, "So far as is known at present, the only typically symbol-using animal existing on earth is the human organism” (p. 810). However, in more recent 
years rhetoric has come to include a wide variety of symbol-using entities within its scope. For example, George A. Kennedy (1992) argued that rhetoric is an energy that exists prior to any speech act and is thus present in communication among animals. The most notable nonhuman symbol-using entity today is perhaps the set of computer technologies — which, admittedly, are designed by human programmers and so perhaps not entirely "nonhuman"-that analyze potential connections across multiple points of data to "understand" particular subjects. In doing so, they demonstrate a rhetorical agency that Burke may not have afforded. Carolyn R. Miller (2007), writing on automation and computer-mediated communication, has defined agency as "the kinetic energy of rhetorical performance," adding that agency must thus "be a property of the rhetorical event or performance itself” (p. 147). In other words, rhetorical activity as it is currently understood is not limited to the purview of humans—it extends to the other actors involved in any persuasive event.

As one of the two central components of rhetoric (the other being the example), the enthymeme has received a tremendous amount of critical attention; in particular, its role above and beyond the context of the incomplete syllogism has been a topic of particular interest (i.e., understanding rhetorical practice as enthymematic rather than identifying the enthymeme as a specific rhetorical device). Jeffrey Walker (1994) has argued in favor of conceptual diversity for the enthymeme, suggesting that enthymemes and enthymematic procedure may be different in different kinds of discourse such as, for example, fiction or poetry, or the belletristic essay, or the various kinds of scholarly, scientific, technical, and administrative prose. We need to consider what enthymemes are like, and how they work, in these discursive realms and at different points in history. (p. 61) 
For Walker, enthymemes perform differently in various contexts and for particular audiences, and their procedural logic must similarly differ to reflect the needs, constraints, and values of those audiences. Walker recognizes the potential for this flexible quality of the enthymeme, which he views as "not only a form of passional reasoning but also an architectonic principle for for both the invention and structuring of suasive discourse” (p. 63). In other words, the enthymeme is not simply a procedure for suggesting a particular idea but a structure upon which to build a persuasive system whose logic relies on the relations implied through the enthymematic foundation.

\subsection{The procedural enthymeme}

In a procedural system, the enthymeme is constructed by means of seemingly related functional operations or rules that together work toward the inducement of some sort of action. For example, in a game of tic-tac-toe, one cannot erase or overwrite his or her opponent's markings and must instead add a new marking in an empty space. A driver, seeing a red traffic light at an intersection, is expected to stop rather than continue through the intersection. Our participation in these systems, whether explicitly or only tacitly acknowledged, is dependent on our willingness to be persuaded by the procedural rules thereof (which, in many cases, relies itself on how easily a rhetor can discern what those rules and anticipated participant behaviors are).

In regards to computational systems in particular, and especially those systems which impact various components of social life, one’s participation therein is increasingly difficult to recognize, and the mechanisms by which one participates are often obscured, sometimes causing the system to appear less visible and more “immediate,” to use the term employed by Jay David 
Bolter and Richard Grusin (2000); at other other times, this obfuscation specifically makes the system difficult to disrupt or "game" for unintended ends.

As a result, as rhetors we often engage in one of the most powerful existing enthymematic activities: we convince ourselves that we are actively making decisions about how to participate in a given system when, in reality, we accept options made apparently available to us from a set of constrained possibilities. In other words, we allow ourselves to be persuaded that we are the only agents involved in a particular situation when, in reality, there are networks of visible and invisible actors working to persuade us to specific ends—often including further participation in relevant persuasive computational systems.

Connected to this erroneous understanding of agency in a procedural situation is the inability of a given individual to evaluate critically the sort of data that he or she is provided as a component of computational interaction. For example, most users of Google’s search engine assume that the first page of results provides the most helpful and relevant links related to a given keyword or set of keywords. However, access to Google’s PageRank system and other algorithms that generate the list of search results is highly restricted—so how can users be sure that they are actually gaining access to the data that they believe have been provided (i.e., the most helpful and relevant links to desired information)? In many cases, it is precisely this sort of ambiguity or obscurity to procedural mechanisms that facilitates users' perceptions of greater agency than may actually be possessed.

In the following section, three cases of computational systems using procedural rhetoric will be explored, in which each employs the procedural enthymeme as a central persuasive tactic. While these cases are meant to demonstrate in part the breadth of influence and impact a procedural system may have on a particular user population, they are also meant to demonstrate 
common qualities of procedural systems working rhetorically toward their own (as well as their developers’ and users’) specific ends.

\section{Three Cases: Matching as Procedural Enthymeme Generation \& Interpretation}

Among the most powerful of contemporary Internet systems is search, in which a user connects to a database of information whose points a networked structure relates together in particular ways that, theoretically, reflect user needs and interests. However, search does not adequately capture these processes; match is a more appropriate term. According to Amit Singhal, a Google Fellow instrumental in the search engine’s 2001 rewrite, "The holy grail of search is to understand what the user wants. Then you are not matching words; you are actually trying to match meaning [emphasis added]" (as cited in Levy, 2010, p. 116). Therefore, how these data are understood to be related by the online dating site, for instance, in fact reflect anticipations of the system developers about what they think users might want — even as, in many cases (as described below re: Match.com), those anticipations may be at odds with the explicitly stated functionality or capability of the system.

A lack of access to the complete inner workings of these systems is an integral component of the rhetorical ecology of each network; because users are understood to invent relationships between data and their needs, the relevant enthymeme- that provided results relate to those users' needs - is essentially accepted without much persuasive labor on the part of the system developers. In these three brief cases, we explore how search-related procedural enthymemes operate in order to support particular paradigms for the use of Google, Match.com, and Facebook. 


\subsection{Google's PageRank and other search results algorithms}

As mentioned above, Google's search engine runs on a number of link-sorting algorithms that use the calculation of numerous variables that determine the "strength" of a particular website in relation to a given keyword or key phrase (e.g., a search for "tomato” should theoretically return links that discuss growing tomatoes in one's garden, cooking dishes where tomato is a central ingredient, and so on). One of Google's most well-known algorithms is "PageRank," an algorithm that calculates website strength based in part on a given page's relationship to other pages, provided via links to and from those pages. While details of some early versions of PageRank and its other ranking algorithms have been published (Brin and Page, 1998; Rogers, 2002; Austin, 2015), the corporation keeps the details of its ranking calculations heavily guarded from possible competitors as well as from individuals or businesses seeking to improve the strength of their website(s) in Google’s search result rankings.

Given Google's near-ubiquity in the realm of online searching, the lack of access to its algorithmic mechanisms plays a significant role in how Google users can, or cannot, recognize how they are persuaded by Google and themselves to make use of the search engine andthe results it provides. Several usability and Search Engine Optimization (SEO) studies have demonstrated that Google users rarely look beyond the first page of search results for a particular query, meaning that the vast majority of users (in some studies, up to 92\%) are willing to accept the premise that the "best" links are provided early and up-front in a list of Google search results (Chitika Insights, 2013; Nielsen, 2005). That is, very few users will navigate beyond a handful of search result pages in order to look for the sort of information they think they're looking for, so the information on result page one or two will inevitably be viewed as more relevant and accurate than information on result page forty-seven. Accordingly, these "best" links are often 
organized due to efforts to customize content for search engines' ranking algorithms as much as for the needs or interests of anticipated users (Killoran, 2010). The resulting set of information provided to users has been described by Eli Pariser (2011) as a filter bubble that promotes access to some links over others because Google’s algorithms calculate that a user might "really" want to access--usually providing information that supports, rather than challenges, a user's existing worldview.

Further, and perhaps frustratingly for the user, Google places paid links—called "Adwords" —at the top of its search result pages. This potentially confuses the matter of “relevant and accurate” results through Google’s inclusion of advertisements—in a prominent position on each page-within its list of results. The issue is complicated further by the fact that the advertisements’ appearance closely resembles that of regular search result links. A 2013 study by British user experience (UX) consulting agency Bunnyfoot found that roughly $40 \%$ of users click on Google's Adwords links instead of the "legitimate" search result links below the Adwords space (Stevens, 2013). The users' reasoning was that they wanted to click on the most relevant links, and they assumed those to be the first results displayed on the page.

Even though the Adwords space has a shaded background to distinguish it visually from the search result list, the prime location of the advertisement space suggested that the paid-for Adwords links were, in fact, the optimal results for each user's searches. Further, Google’s use of advertisements is not limited to links with "relevant" terms or thematic content but extends into personalization, as the site displays advertisements that are meant to target an individual's interests as represented by his or her search patterns over time. It is entirely possible that Adwords links look especially enticing as optimal results because they may reflect user choices from prior searches or the trends that have emerged from continued use of Google's search 
engine. In fact, PageRank and Adwords both function most effectively when users provide "honest” or "accurate" information about themselves and their interests to Google’s various systems; when search behaviors or personal details--such as in the manager screen for Google Ads Settings--are changed dramatically, displayed search results and ads attempt to provide a user with links that may, in reality, reflect nothing of that user's interests. For example, Datta, Tschantz, and Datta (2015) have demonstrated that even a simple change in a user profile’s reported details can result in very different ads, such as in job postings for users set as "male" having a higher likelihood of viewing ads for high-paying jobs than users set as "female” (p. 93).

Effectively, Google’s ranking algorithm—and its AdWords space for personalized solicitations on any page of search results—can help rhetoricians recognize Bogost's (2008) argument that a user (in Bogost's case, specifically a video game player) can "see the ways the processes inscribed in the system work” (p. 121). Google users are expected to provide query keywords and phrases for topics that interest them; Google then provides web pages that ostensibly match users' queries (whether syntactically or semantically), albeit with paid advertisements "hiding" in the result lists. The search engine may work mechanically through complex keyword matching and link ranking, but what it demonstrates rhetorically is the cultivation of a data set about any given user that will ultimately operate to monetize the user's interests and browsing behavior. The expected event—discovery of information about a given topic of interest, thanks to the implicit argument that Google serves users with avenues toward the knowledge that they seek—mutates into an unexpected one, as the procedural enthymeme reveals a different conclusion than the one suggested by its premises: the genesis of a consumer who is persuaded by the Google interface (and who may persuade the PageRank algorithm to 
provide a particular body of search results) that emphasizes links to the websites of one or more of Google’s advertising partners.

\subsection{Match.com and online dating}

Like Google and other Internet search engines, online dating sites rely on complex algorithms to match users with one another, and these processes used to identify potential paramours are closely guarded secrets. According to Sam Yagan, CEO of Match, Inc., the company behind popular dating sites Match.com and OKCupid.com as well as dating app Tinder, Match.com uses a combination of filtering and ranking procedures to faciliate pairings that will likely lead to a good first date (Shontell, 2013). Initially the site hard filters for individuals who a) fall within the preferred demographic and location ranges of the user and b) meet the "dealbreakers," those requirements for which the user has a strong preference (e.g., smoking habits). Then, hard-filter results are ranked based on the stated preferences (interests, pastimes, beliefs, etc.) that indicate the probability for a high volume of on-site communication; Match.com sees this as a predictor of the likelihood for a good conversation-and therefore a good first date (Shontell, 2013). Across interactions with the user, Match.com continues to filter and rank its recommendations based on adjustments to the users' stated preferences as well as revealed preferences, behaviors such as profile viewing and messaging (Paumgarten, 2011). In other words, if a user has stated a strong preference for nonsmokers but revealed a lack of such preference by consistently visiting the profiles of tall blondes, regardless of their smoking habits, matching criteria will be expanded to include tall, blonde smokers. Significantly, the reason given for a match may not communicate the actual rationale behind it. In the case of the tall,

blonde smoker, Match.com may indicate that two members were introduced because of a shared interest in travel or dining out, in order to obscure its reliance of users' profile-viewing habits 
(Gould, 2009). In addition, much like Google’s AdWords placement, premium subscribers are included in the initial message sent to new users who fit within their preferences, regardless of whether the premium subscriber meets the preferences of the new user.

Online dating sites draw on (and circulate within) larger cultural narratives, both old and new, about romantic love, sexuality, and the importance of marriage; however, they provide little information to their users on how they actually work. In the case of Match.com, the site's logics try to facilitate "good first dates." The system is predicated on the notion that "everyone knows dating is a numbers game” and that the more good dates users have, the more likely they are to find a partner (Shontell, 2013). Match.com’s advertising and on-site marketing highlight the importance of dating. One recent television campaign featured the tagline, "[M]ore dates, more relationships, and more marriages than any other site," and the screen claims the status of “\#1 in dates, relationships and marriages.” Site procedural systems obscure this primacy of dating. Users not only provide information on their appearance, lifestyle, background, and interests but also answer questions (with over six-hundred variables) about their matches' characteristics, despite the fact that Yagan has argued that "people don't always know what's important to them" (Shontell, 2013). He suggests, for example, that individuals may hold an emotional connection to their political beliefs and highly value the political affiliation of their matches but that they may visit the profiles of, or exchange on-site messages with, site participants with oppositional political leanings. Match.com uses those revealed preferences to filter and rank match results. However, the user experience of site procedures give the impression that Match.com is about “real” compatibility, based solely or primarily on information provided explicitly by the user rather than on the "numbers game” of statistical, behavior-influenced computation. 
Match.com's procedural enthymeme reveals an argument about the difference between claim and performance. What users purport to value and what they demonstrate valuing may not be easily reconciled. At the same time, site procedures rely on users' emotional investments to persuade them into participating, regardless of whether closely held beliefs, such as political affiliation, play a role in matching users. When certain mechanisms (e.g., premises) of a particular enthymeme are revealed (and which, recalling Lanham, allow one to look "at," rather than "through," the procedural system and its argument), users may attempt to modify their claims in proportion to what they believe the enthymeme will reveal when it is realized in practice. In essence, rhetors perform a kind of deliberation with procedural agents to negotiate the terms or scope of a given argument, attempting to "bend" or "break" the rules of the system, echoing Morpheus from The Matrix in the epigraph to this article. But, much like the Matrix, Match.com is flexible, modulating to incorporate what users both state and reveal about their preferences. As Match.com's computations suggest, users may be unable to recognize—let alone alter fundamentally—those variables that the procedural system perceives and communicates as being crucial to the rhetorical event.

\subsection{Facebook's graph search}

The Tumblr blog “Actual Facebook Graph Searches,” curated briefly by Tom Scott in January 2013, has demonstrated a nuanced examination of the then-newly-unveiled Facebook graph search function, a tool that presumably facilitated Facebook users' attempt to locate information of value to them and their friends in a more accurate and user-friendly manner than a simple search bar might allow. However, the graph search tool has thus far invariably been demonstrated to provide far more — and, just as frequently, far different—information than might be desired, both by the searcher and by the individuals whose profiles have been scraped to 
generate the information provided in a set of search results. Facebook has claimed that this tool gives agency to users: “you can always review the things you've shared on Facebook and change who can see them. You can also ask other people to remove photos or other posts” (2015). However, a number of users—including Scott (2013)—have argued that Facebook's search capabilities extend far beyond the privacy settings implemented by individual users, suggesting that the ways it can be used have, probably obviously to you all, not been fully evaluated.

Scott (2013) has demonstrated, through his blog's screenshots of actual searches (with the following examples' search term variables displayed in bolded text), a number of powerful procedural enthymemes whose ultimate potential for action are the variables left implicit. One of the last posts to the blog was for "Current Tesco employees who like Horses." Tesco, for those who may be unaware of the company, is a British grocery chain that came under scrutiny for selling some meat products, such as hamburgers, containing horse meat. What does the search persuade one to do beyond chuckle? Perhaps one could take action by contacting those employees to see whether their appreciation for horses is greater than that for their employer. It is important to note that this is a specific case of a technologically mediated database combed procedurally to help users draw conclusions about a specific set of information. However, more generally, it's a procedure by which someone can use generalizations or stereotypes about individuals' interests to make some meaningful point.

In another post, Scott displays the results for "Married people who like Prostitutes." The post's screenshot includes a large, bright red arrow pointing to a means by which the search parameters can be altered, allowing an interested or motivated party to view not the Facebook users in the current list but instead the spouses of those users. The point is not explicitly stated, but one can figure out what the possible consequence could be by contacting those spouses and 
making them aware of the connection Facebook allowed us to make. Similarly, there is a post focused on "People who like Focus on the Family and Neil Patrick Harris," drawing attention to the apparent paradox between supporting a group who advocates against gay marriage and being a fan of a prominent gay actor.

Even more dangerously, as demonstrated by yet another post on the Tumblr site, Facebook's graph search allows users to search for conditions such as "Islamic men interested in men living in Tehran, Iran.” Another "helpful” arrow draws our attention to a search tweak so that one might see "Places where they've worked.” What might the consequences be from an individual making use of the results of this procedure for violent and hateful aims? Do these searches suggest a power and literacy available to an informed public? Or do they suggest a set of tools and skills which can be used against that public by a subset thereof?

What “Actual Facebook Graph Searches” demonstrates, perhaps more than anything else, is that the capacity or potential of an algorithm for inventing avenues for rhetorical activity possesses exponentially greater power and significance than the sum of its actual parts. That is, the possibility for Graph Search’s persuasive power to impact numerous and diverse populations - whether through expected or unexpected avenues of communication or data correlation—vastly overwhelms any individual set of search results, what Hairston (1986) identified as the goal of an enthymeme "to establish probability, not certainty" (p. 62). The algorithm's mechanisms become most noticeable when that potential is complemented by one or more agents seeking particular ends that may not be easily aligned with the purported functional intent of the algorithm. In other words, an agent's ability to construct particular enthymemes through the procedures of a particular computational system can be incredibly persuasive when employed kairotically. Further, the example of Facebook Graph Search demonstrates that 
developer intent is not as wholly constraining in regards to the capabilities of a procedural system as one might initially believe; instead, a critically and rhetorically literate rhetor (or corhetor, working in concert with the capacities of a technological system) may discover entirely new arguments that can dramatically change the trajectory of a given enthymeme.

\section{Conclusions}

Google, Match.com, and Facebook all make use of their procedural systems for incredibly powerful rhetorical ends: users' attempts to interact with components of these systems provide them with access to components thereof, with incomplete syllogisms implying certainor at least preferable-ways to interpret the results of those users' interactions. In each case, the site suggests a certain form of agency to belong to the user, even as actual use demonstrates that such agency may not accurately reflect how that site operates beyond the boundaries of user access. As a result, we users are invited to complete their syllogisms and argue on these systems' behalf that we, rather than any of the sites or their developers, are creating and locating the kind of information we're interested in, especially as individual points of data relate to others. In other words, we become mechanisms in the procedural systems that facilitate these computational search technologies and the interpretations that can potentially be invented from result data.

That said, computational systems are not by any means limited to electronic or digital technologies or to computers specifically. However, such systems provide an increasingly effective means of iterating through potential outcomes--in terms of both processing "power,” (to navigate through numerous variables and points of data) and processing speed (to generate results quickly)--in order to assist rhetors with the construction of their arguments and the facilitation of any subsequent action. A system's intended purpose ultimately becomes incidental to the purposes toward which it can be employed; indeed, that intent is itself a component of an 
enthymematic logic, with the user/audience expected to reach a conclusion connecting together possibility with intent. For example, one might complete the following enthymeme:

Premise: This system was developed [is intended] to perform this task.

Premise: This system can be used [has the potential] to perform this task.

(Implicit) conclusion: This system should be chosen to perform this task.

As the above case studies demonstrate, however, it is also possible to reach other conclusions, or to construct divergent premises, building on such related questions as "What other tasks might this system be capable of performing?” or “Can this system perform tasks opposing or conflicting those it was developed to perform?” or even “Are there alternative systems that might be preferable to perform this task in this particular situation?” Further, one might ask whether a given system is already performing other tasks, or performing this task in other ways, than one can accurately recognize occurring. One logical conclusion is not the only potential conclusion, since different groups or individuals may interpret "intent” or "purpose” in varying and opposing ways from one another.

As a result, it behooves us—scholars of rhetoric and composition, scholars of digital media, professional and amateur developers of software programs, and users of said programsto attend closely and critically to the constraints and affordances that we tacitly or explicitly assume and accept as existing in regards to the procedural systems we employ for all manner of purpose in our daily lives. The influence such assumptions have upon our activities (those we think we initiate or are otherwise in control of as well as those we may believe to be catalyzed by other agents) has the potential to be significant, and this significance only increases if we refuse to acknowledge the persuasive power of that influence. Procedural systems are not neutral, inert tools for us to use as we desire, with no consequence or impact beyond the immediate context of 
such use. Rather, they are complex and active rhetorical agents who make arguments to and through us via the activities they assist us with, and hinder us from, completing. 


\section{Reference List}

Aristotle. (1991). On rhetoric: A theory of civic discourse. (George A. Kennedy, Trans.). Oxford: Oxford University Press.

Austin, David. (2015). How Google finds your needle in the Web’s haystack. American Mathematical Society. Retrieved from http://www.ams.org/samplings/featurecolumn/fcarc-pagerank

Ballentine, Brian. (2015). Textual adventures: Writing and game development in the undergraduate classroom. Computers and Composition, 37(1), 31-43.

Barnett, Scot. (2010). Toward an object-oriented rhetoric: A review of Tool-being: Heidegger and the metaphysics of objects and Guerrilla metaphysics: Phenomenology and the carpentry of things by Graham Harman. Enculturation, 7. Retrieved from http://enculturation.net/toward-an-object-oriented-rhetoric

Bolter, Jay David and Richard Grusin. (2000). Remediation: Understanding new media. Cambridge: MIT Press.

Bogost, Ian. (2007a). Persuasion and gamespace. In Friederich von Borries, Steffen P. Walz, \& Matthias Böttger (Eds.), Space time play: Computer games, architecture and urbanism: The next level (pp. 304-307). Boston: Birkhäuser.

Bogost, Ian. (2007b). Persuasive games: The expressive power of videogames. Cambridge: MIT Press.

Bogost, Ian. (2008). The rhetoric of video games. In Katie Salen (Ed.), The ecology of video games: Connecting youth, games, and learning (pp. 117-139). Cambridge: MIT Press.

Brin, Sergey and Lawrence Page. (1998). The anatomy of a large-scale hypertextual web search engine. Computer Networks and ISDN Systems, 30, 107-117. 
Brock, Kevin. (2012). One hundred thousand billion processes: Oulipian computation and the composition of digital cybertexts. Technoculture, 2. Retrieved from http://tcjournal.org/drupal/vol2/brock

Brown, James J., Jr. (2011).The decorum of objects. Clinamen. Retrieved from http://clinamen.jamesjbrownjr.net/2011/09/12/the-decorum-of-objects/

Brown, James J., Jr. (2015). Crossing state lines: Rhetoric and software studies. In Jim Ridolfo and William Hart-Davidson (Eds.), Rhetoric and the digital humanities (pp. 20-32). Chicago: University of Chicago Press.

Burke, Kenneth. (1969). A rhetoric of motives. Berkeley, CA: University of California Press. Burke, Kenneth. (1978). (Nonsymbolic) motion/(symbolic) action. Critical Inquiry, 4(4), 809838.

Chitika Insights. (2013). The value of Google result positioning. Chitika | Online Advertising Network. Retrieved from http://chitika.com/google-positioning-value

Colby, Richard. (2014). Writing and assessing procedural rhetoric in student-produced video games. Computers and Composition, 31(1), 43-52.

Cooper, Marilyn M. (2011). Rhetorical agency as emergent and enacted. College Composition and Communication, 62(3), 420-449.

Cox, Geoff with Alex McLean. (2012). Speaking code: Coding as aesthetic and political expression. Cambridge, MA: MIT Press.

Datta, Amit, Michael Carl Tschantz, and Anupam Datta. (2015). Automated experiments on Ad Privacy Settings: A tale of opacity, choice, and discrimination. Proceedings on Privacy Enhancing Technologies, 2015(1), 92-112. 
Gould, Emily. (2009). True match. MIT Technology Review, 73-75. Retrieved from http://www.technologyreview.com/review/416811/true-match/

Hairston, Maxine C. (1986). Bringing Aristotle’s enthymeme into the composition classroom. In Jean Dietz Moss (Ed.), Rhetoric and praxis: The contribution of classical rhetoric to practical reasoning (pp. 59-77). Washington, D.C.: The Catholic University of America Press.

Facebook. (2015). Facebook search. Facebook. Retrieved from http://search.fb.com/ Hour of Code. (2015). Hour of Code. Retrieved from https://hourofcode.com/

Kennedy, George A. (1992). A hoot in the dark: The evolution of general rhetoric. Philosophy and Rhetoric, 25(1), 1-21.

Killoran, John B. (2010). Writing for robots: Search engine optimization of technical communication business web sites. Technical Communication, 57(2), 161-181.

King, Matt. (2010). Procedural rhetorics / rhetoric's procedures: Rhetorical peaks and what it means to win the game. Currents in Electronic Literacy. Retrieved from http://currents.dwrl.utexas.edu/2010/king_procedural_rhetorics_rhetorics_procedures

Lanham, Richard. (1993). The electronic word: Democracy, technology, and the arts. Chicago: University of Chicago Press.

Levy, Steven. (2010, March). Inside the box. Wired Magazine 18(3). Retrieved from http://www.wired.com/2010/02/ff_google_algorithm/.

Nielsen, Jakob. (2005). The power of defaults. Nielsen Norman Group. Retrieved from http://www.nngroup.com/articles/the-power-of-defaults/

Pariser, Eli. (2011). The filter bubble: What the Internet is hiding from you. New York: Penguin Press. 
Paumgarten, Nick. (2011, July 4). Looking for someone: Sex, love, and loneliness on the Internet. The New Yorker. Retrieved from http://www.newyorker.com/magazine/2011/07/04/looking-for-someone

Raja, Tasneem. (2014). We can code it! Why computer literacy is key to winning the 21st century. Mother Jones. Retrieved from http://www.motherjones.com/media/2014/06/computer-science-programming-codediversity-sexism-education

Reid, Alex. (2010). Post-procedural rhetoric and serious games. Digital Digs: An Archeology of the Future. Retrieved from http://alex-reid.net/2010/03/postprocedural-rhetoric-andserious-games.html

Rickert, Thomas. (2013). Ambient rhetoric: The attunements of rhetorical being. Pittsburgh: University of Pittsburgh Press.

Rogers, Ian. (2002). The Google PageRank algorithm and how it works. Ian Rogers. Retrieved from http://www.sirgroane.net/google-page-rank/

Rushkoff, Douglas. (2012, December 10). CNN: What I'm telling Congress on Wednesday: Teach kids to code. Rushkoff. Retrieved from http://www.rushkoff.com/blog/2012/12/10/cnn-what-im-telling-congress-on-wednesdayteach-kids-code.html

Scott, Tom. (2013). Actual Facebook graph searches. Tumblr. Retrieved from http://actualfacebookgraphsearches.tumblr.com/

Selber, Stuart A. (2004). Multiliteracies for a digital age. Carbondale: Southern Illinois University Press. 
Shontell, Alyson. (2013). Match Inc. CEO Sam Yagan reveals how math and data predict love online. Business Insider. Retrieved from http://www.businessinsider.com/how-onlinedating-sites-work-2013-5?op=1

Stevens, Robert. (2013). 40\% of customers don’t know that Google Adwords are adverts. Bunnyfoot. Retrieved from http://www.bunnyfoot.com/blog/2013/02/40-of-customersdont-know-that-google-adwords-are-adverts/

Storment, Molly. (2011). Using games to teach procedural rhetoric. HASTAC. Retrieved from http://www.hastac.org/blogs/mhstorment/2011/10/22/using-games-teach-proceduralrhetoric

Thominet, Luke. (2012). Procedural rhetoric. Composition + Videogames. Retrieved from http://sites.google.com/site/composingvideogames/six-levels-of/level-4-critical-gamestudies/procedural-rhetoric

Vee, Annette. (2012). Text, speech, machine: Metaphors for computer code in the law. Computational Culture: A Journal of Software Studies, 2. Retrieved from http://computationalculture.net/article/text-speech-machine-metaphors-for-computercode-in-the-law

Walker, Jeffrey. (1994). The body of persuasion: A theory of the enthymeme. College English, 